\title{
DISC1 pathway in brain development: exploring therapeutic targets for major psychiatric disorders
}

\author{
Atsushi Kamiya $^{1}{ }^{*}$, Thomas W. Sedlak ${ }^{1 *}$ and Mikhail V. Pletnikov ${ }^{1,2 *}$ \\ ${ }^{1}$ Department of Psychiatry and Behavioral Sciences, Johns Hopkins University School of Medicine, Baltimore, MD, USA \\ ${ }^{2}$ Department of Neuroscience, Johns Hopkins University School of Medicine, Baltimore, MD, USA
}

\section{Edited by:}

Daniela Tropea, Trinity College Dublin Ireland

\section{Reviewed by:}

Xiangning Chen, Virginia

Commonwealth University, USA

Ju Wang, University of Virginia, USA

*Correspondence:

Atsushi Kamiya, Thomas W. Sedlak and Mikhail V. Pletnikov, Department of Psychiatry and Behavioral

Sciences, Johns Hopkins University

School of Medicine, Baltimore, MD

21287, USA.

e-mail: akamiya1@jhmi.edu;

tsedlak@jhmi.edu; mpletnik@jhmi.edu
Genetic risk factors for major psychiatric disorders play key roles in neurodevelopment. Thus, exploring the molecular pathways of risk genes is important not only for understanding the molecular mechanisms underlying brain development, but also to decipher how genetic disturbances affect brain maturation and functioning relevant to major mental illnesses. During the last decade, there has been significant progress in determining the mechanisms whereby risk genes impact brain development. Nonetheless, given that the majority of psychiatric disorders have etiological complexities encompassing multiple risk genes and environmental factors, the biological mechanisms of these diseases remain poorly understood. How can we move forward to our research for discovery of the biological markers and novel therapeutic targets for major mental disorders? Here we review recent progress in the neurobiology of disrupted in schizophrenia 1 (DISC1), a major risk gene for major mental disorders, with a particular focus on its roles in cerebral cortex development. Convergent findings implicate DISC1 as part of a large, multi-step pathway implicated in various cellular processes and signal transduction. We discuss links between the DISC1 pathway and environmental factors, such as immune/inflammatory responses, which may suggest novel therapeutic targets. Existing treatments for major mental disorders are hampered by a limited number of pharmacological targets. Consequently, elucidation of the DISC1 pathway, and its association with neuropsychiatric disorders, may offer hope for novel treatment interventions.

Keywords: DISC1, cerebral cortex development, genetic risk factors, major mental disorder, immune responses

\section{INTRODUCTION}

Disrupted in schizophrenia 1 (DISC1) was initially discovered at the breakpoint in a balanced chromosomal translocation $\mathrm{t}(1 ; 11)$ segregating with major mental conditions, such as schizophrenia, bipolar disorder, and major depression in a Scottish pedigree (Millar et al., 2000). Since then, accumulating evidence from genetic studies indicated that DISC1 is not only associated with schizophrenia and mood disorders, but also other psychiatric disorders of neurodevelopmental origin, such as autism, Asperger syndrome, and agenesis of the corpus callosum (Hennah et al., 2003; Hodgkinson et al., 2004; Callicott et al., 2005; Kilpinen et al., 2008; Song et al., 2008, 2010; Osbun et al., 2011). Although recent genome wide association studies (GWAS) have not found DISC1 as a key genetic risk factor for patients met the current diagnostic criteria for schizophrenia (Purcell et al., 2009; Stefansson et al., 2009; Mathieson et al., 2011), it is noted that variations of DISC1 influence anatomical and functional endophenotypes even in control subjects (Thomson et al., 2005; Di Giorgio et al., 2008; Prata et al., 2008; Tomppo et al., 2009b). Collectively, genetic variation of DISC1 may confer vulnerabilities to a wide range of neurodevelopmental psychiatric conditions by affecting brain maturation, thereby modifying brain function.

Consistently, extensive biological studies indicate that DISC1 plays a role in multiple cellular processes during and after brain development (Chubb et al., 2008; Brandon and Sawa, 2011). In fact, many protein binding partners of DISC1 are associated with various molecular pathways that regulate fundamental cellular processes for brain development and function (Table 1). Nonetheless, it is still unknown which functional aspects of DISC1 directly affect molecular mechanisms underlying disease susceptibility. How can we utilize accumulating biological data of DISC1 to discover novel therapeutic targets and biological markers for major mental conditions? Here, we will review DISC1-associated molecular pathways which have the potential to be novel therapeutic targets, with particular focus on well documented DISC1 pathways involved in cerebral cortex development and function (Figure 1). We will also discuss the potential link of DISC1 pathways and environmental factors, such as immune/inflammatory responses, to explore therapeutic interventions based on understanding disease mechanisms of genetic and environmental interaction.

\section{DISC1 IN CEREBRAL CORTEX DEVELOPMENT}

Disrupted in schizophrenia 1 plays a critical role for the regulation of cell proliferation in the developing cerebral cortex via the canonical Wnt signaling pathway (Mao et al., 2009). The data suggested that DISC1 inhibits the activity of glycogen synthase kinase 3 beta (GSK3 $\beta$ ) via protein interaction, thereby stabilizing $\beta$-catenin which is required for proper progenitor proliferation through Wnt pathway. The same group later reported that DIX domain containing-1 (DIXDC1), a homolog of the Wnt signaling genes 
Table 1 | DISC1 interacting proteins and functions.

\begin{tabular}{|c|c|c|c|}
\hline DISC1 interactor & Function & Risk gene & Reference \\
\hline NDEL1 & Neurite extension, migration & + & $\begin{array}{l}\text { Morris et al. (2003), Ozeki et al. (2003), Kamiya et al. (2005), } \\
\text { Taya et al. (2007), Burdick et al. (2008) }\end{array}$ \\
\hline NDE1 & Proliferation & + & Burdick et al. (2008), Bradshaw et al. (2009) \\
\hline PCM1 & Microtubule organization & + & Kamiya et al. (2008) \\
\hline $14-3-3 \varepsilon$ & Migration axon growth & + & Taya et al. (2007) \\
\hline FEZ1 & Neurite extension & + & Miyoshi et al. (2003) \\
\hline Kendrin & Centrosome function & - & Miyoshi et al. (2004) \\
\hline MAP1A & Microtubule associated & - & Morris et al. (2003) \\
\hline MIPT3 & Microtubule associated & - & Morris et al. (2003) \\
\hline \multicolumn{4}{|l|}{ NUCLEUS } \\
\hline ATF4 & Transcription factor & - & Morris et al. (2003), Sawamura et al. (2008) \\
\hline $\mathrm{N}-\mathrm{CoR}$ & Corepressor for gene transcription & - & Sawamura et al. (2008) \\
\hline \multicolumn{4}{|l|}{ OTHER } \\
\hline PDE4B & cAMP signaling & + & Millar et al. (2005) \\
\hline Girdin & AKT signaling & + & Enomoto et al. (2009), Kim et al. (2009) \\
\hline Grb2 & Tyrosine kinase mediated signal transduction & - & Shinoda et al. (2007) \\
\hline DBZ & PACAP signaling & - & Hattori et al. (2007) \\
\hline Mitofilin & Mitochondrial function & - & Park et al. (2010) \\
\hline
\end{tabular}

Many protein binding partners of DISC1 have been reported. DISC1 may function as an anchoring molecule to regulate various molecular pathways via interaction with said protein interactors in a context dependent manner.

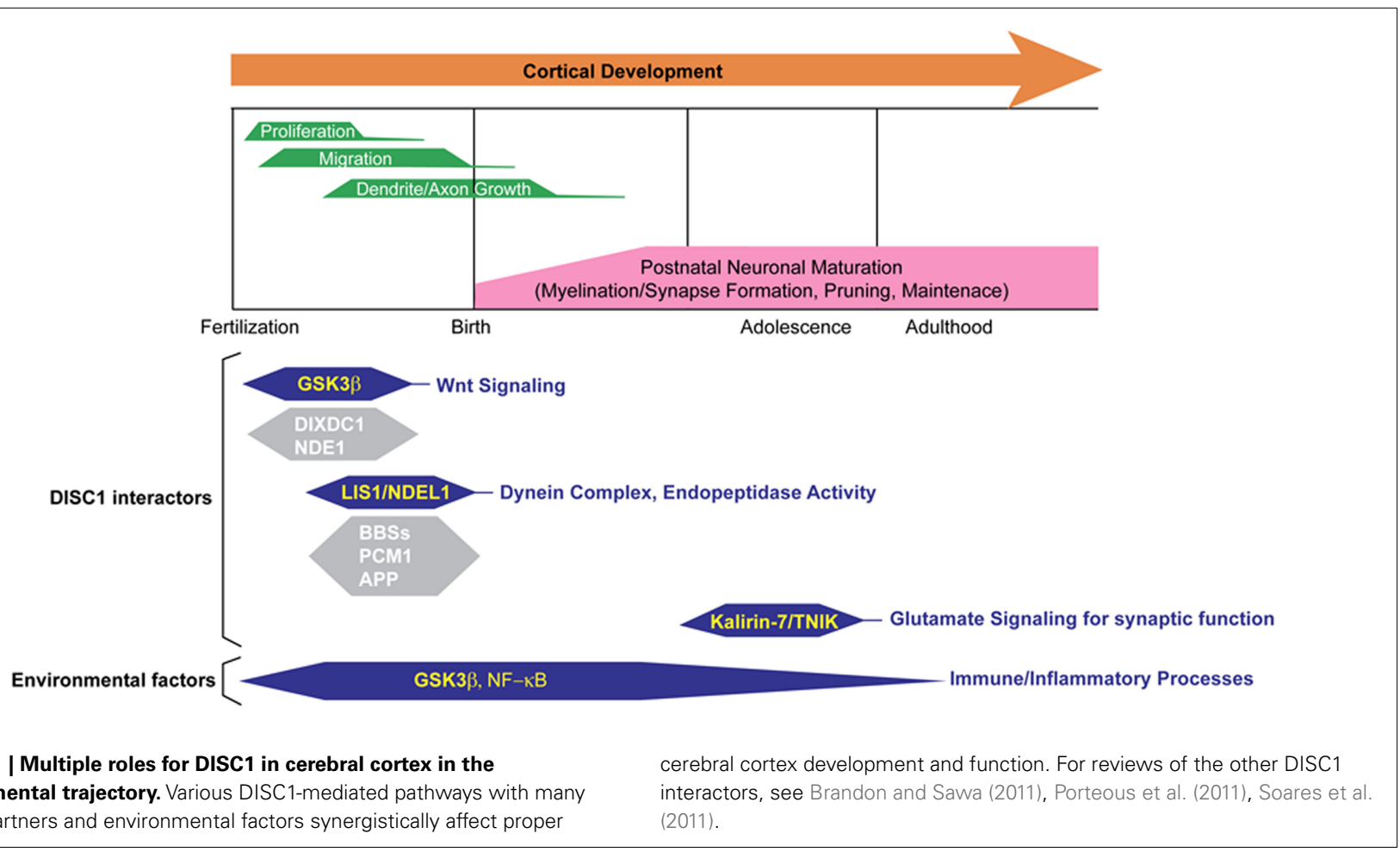


Disheveled axin, interacts with DISC1 to co-modulate GSK3 $\beta / \beta$ catenin signaling for proper cell proliferation (Singh et al., 2010). Accumulating evidences have shown that GSK3 $\beta$ signaling may be involved in various neuropsychiatric disorders, such as schizophrenia, autism, and Alzheimer's disease, suggesting that GSK3 $\beta$ appears as a prominent therapeutic target for mental disorders (Bachmann et al., 2005; Hur and Zhou, 2010). In fact, lithium, the mood stabilizer which is commonly used for the treatment of bipolar disorder, is known to inhibit GSK3 activity (Stambolic et al., 1996). The other psychoactive drugs, such as clozapine, risperidone, and valproic acid, have also been reported to affect GSK3 $\beta$ activity (Stambolic et al., 1996; Kang et al., 2004; Li et al., 2007; Rowe et al., 2007). Nonetheless, since GSK3 $\beta$ regulates various downstream effectors, which are not only implicated in the Wnt pathway, but also other signaling required for cellular development, such as sonic hedgehog and Notch signaling pathways (Hur and Zhou, 2010), it is important to examine specific GSK3 $\beta$ mediated pathways relevant to disease mechanisms to find novel therapeutic strategies. In this regard, it may be ideal to focus on DISC1-mediated GSK3 $\beta$ pathways, especially those in association with other genetic risk factors, to explore disease-associated molecular mechanisms. For instance, collapsin response mediator protein-2 (CRMP-2)/dihydropyrimidinase-like-2 (DPYSL2), a susceptibility gene for schizophrenia (Nakata et al., 2003), is reported to be a potential protein interactor of DISC1 by yeasttwo-hybrid screening (Camargo et al., 2007). Interestingly, CRMP2/DPYSL2 is known to be phosphorylated by GSK3 $\beta$ for the regulation of axon outgrowth (Yoshimura et al., 2005).

Neuronal migration is a fundamental cellular process that is required for proper cortical organization. Many groups have consistently reported that knockdown of DISC1 using RNA interference (RNAi) impaired radial neuronal migration in the developing cerebral cortex (Kamiya et al., 2005, 2008; Kubo et al., 2010; Singh et al., 2010; Young-Pearse et al., 2010; Ishizuka et al., 2011). Findings from these studies suggest that DISC1, along with many protein binding partners, regulate neuronal migration via centrosome and microtubule-dependent mechanisms. Of note, some of these binding partners are known as risk or causative genes for various neuropsychiatric disorders. These include nuclear distribution element-like (NDEL1) and pericentriolar material 1 (PCM1), risk genes for schizophrenia, and BBS4, a causative gene for BardetBiedl syndrome that frequently accompanies impaired cognition, mental retardation, and psychosis (Burdick et al., 2008; Kamiya et al., 2008; Tomppo et al., 2009a). Amyloid precursor protein (APP) also interacts with DISC1 to recruit DISC1 to the centrosome for regulation of neuronal migration (Young-Pearse et al., 2010). Furthermore, DISC1 is a component of the LIS1/dynein motor complex (Kamiya et al., 2005). Mutations in human LIS1 gene cause classical lissencephaly resulting in mental retardation (Pilz et al., 1998). Consistently, LIS1 heterozygous knockout mice in which LIS1 expression is reduced, display disorganization of proper cortical layer formation and behavioral abnormalities, such as impaired spatial learning and motor function, indicating that this is a good animal model for human lissencephaly caused by LIS1 haploinsufficiency (Hirotsune et al., 1998). Interestingly, the prenatal administration of ALLN, a calpain inhibitor which prevents the degradation of LIS1, is effective to ameliorate neuronal migration defect and improve motor coordination in this animal model (Yamada et al., 2009).

Although mental disorders undoubtedly have genetic complexities and could not be explained by the simple "haploinsufficiency" model as the case of lissencephaly, elucidation of risk genes, and/or molecules in their interactome, specifically ones with enzymatic activity, may offer hope for novel treatment interventions for neuropsychiatric disorders. In this regard, endo-oligopeptidase activity of NDEL1 is quite interesting from a drug discovery viewpoint (Hayashi et al., 2005). As a matter of fact, inhibitors of angiotensin-converting enzyme (ACE), an exopeptidase, are currently being used to treat hypertension and renal disease (Izzo and Weir, 2011), making peptidase activity an attractive drug target. Although endogenous substrates for NDEL1-oligopeptidase in brain development remain unknown, in vitro experiments identified several oligopeptides, such as neurotensin and bradykinin, as potential targets for NDEL1 (Camargo et al., 1983). Interestingly, neurotensin has a modulatory effect on neurotransmitter systems, including dopaminergic neurons, which may be involved in the pathophysiologies of schizophrenia (Boules et al., 2007).

Posttranslational modifications, which affect the functional diversity of target proteins, could also have potential as novel drug targets and biological markers in the DISC1 pathways. We have recently reported that phosphorylation of DISC1 at Serine 710 is a molecular switch signaling from cell proliferation to neuronal migration in the developing cerebral cortex (Ishizuka et al., 2011). By utilizing in utero electroporation, this study has shown that a phosphor-dead mutant DISC1 can rescue only the proliferation defect elicited by DISC1 knockdown, whereas a phosphor-mimic mutant of DISC1 can exclusively recover impaired migration. The question arises whether the phosphorylation of DISC1 at Serine 710 may be involved in the pathophysiologies of major mental disorders, such as schizophrenia. It is obviously impractical to investigate the phosphorylation status of DISC1 in the developing human brain from subjects at risk of developing schizophrenia. Nonetheless, recent progress in induced pluripotent stem (iPS) cell technology will open new avenues to characterize such findings from preclinical studies using patient-derived neuronal cells, which might in turn identify biological markers for major mental disorders.

\section{DISC1 AND GLUTAMATE SIGNALING FOR SYNAPTIC FUNCTION}

Disrupted in schizophrenia 1 impacts upon brain development may be a challenge for treatment intervention. However, synaptic deficits revealed by the DISC1 pathway offer some potential for development of targeted pharmacologic intervention. Early reports suggested a role for DISC1 in neurite outgrowth (Miyoshi et al., 2003; Ozeki et al., 2003). Subsequent findings underline roles for DISC1 in regulating dendritic spines of the glutamate synapse (Hayashi-Takagi et al., 2010). Rac1 is activated by Karilin-7, leading to increased spine size following NMDA glutamate receptor activation. However, DISC1 appears to interact with Karilin-7, preventing access to and activation of Racl until NMDA receptor activation promotes release of Kal-7 and spine enlargement. Pharmacologic tools to modulate the Karilin-7/DISC1 interaction might be a means to regulate spine maintenance. 
TRAF2- and NCK-interacting kinase (TNIK) represents another potential pharmacological target in the DISC1 protein interaction network. TNIK is found in postsynaptic densities and regulates c-Jun kinase, the actin cytoskeleton and a number of Wnt pathway effectors (Fu et al., 1999; Taira et al., 2004; Mahmoudi et al., 2009). Genetic association studies have found single-nucleotide polymorphisms of TNIK associated with schizophrenia (Potkin et al., 2009; Shi et al., 2009). TNIK mRNA expression was increased in the dorsolateral prefrontal cortex of schizophrenia subjects (Glatt et al., 2005) and in lymphoblasts of monozygotic twins discordant for bipolar disorder (Matigian et al., 2007). A yeast-two-hybrid screen using DISC1 as "bait" identified TNIK as an interactor (Camargo et al., 2007). Subsequently, TNIK and DISC1 were shown to interact in mouse brain (Wang et al., 2011). DISC1 was found to inhibit the kinase activity of TNIK, an action that could be reproduced by a small peptide derived from the DISC1 interaction site. This DISC1 peptide led to increased actin polymerization and decreased expression of a number of postsynaptic density proteins, including PSD95, stargazin, AMPA receptor subunit GluR1 and TNIK, itself (Wang et al., 2011).

\section{DISC1 AND NEUROIMMUNE/INFLAMMATORY PROCESSES}

Microbial infections have been recognized as environmental factors responsible for the increased incidence of schizophrenia and associated disorders (Brown and Derkits, 2010; Sham et al., 1992; Torrey and Yolken, 2003). These reports have been supported by the epidemiological findings of an association between elevated cytokines in maternal serum and schizophrenia in the offspring (DeLisi and Wyatt, 1982; Patterson, 2007; Miller et al., 2009). Subsequently, it has been demonstrated that it is the maternal immune response to a microbe that may contribute to the increased risk of schizophrenia. The role of cytokines in innate immune response makes them promising candidates for studying their functions in disruption of fetal brain development in vulnerable individuals (Dantzer et al., 2008). Most studies with prenatal immune activation have thus far used wild-type mice and rats. However, recently, there have been several reports on developing and characterizing animal models based on combining prenatal immune activation with genetic mutations relevant to schizophrenia (Ibi et al., 2010; Ehninger et al., 2012).

We have been studying possible roles for DISC1 in modulation of poly I:C-induced immune activation in pregnant mice to mimic prenatal in utero exposure to viruses as a model of geneenvironment interactions relevant to schizophrenia (Abazyan et al., 2010). Our findings have suggested that DISC1 may be involved in mediating neuroimmune interplay in this mouse model. Given the extended interactome of DISC1, it is not surprising that this protein is at the crossroads of the signaling transduction pathways activated by immune factors.

One can envision multiple interactions between the pathways impacted by mutant DISC1 and activated by cytokines and/or bacterial lipopolysaccharide (LPS) and poly I:C itself via cytokine receptors or toll-like receptors (TLR) expressed by neurons or glia cells, respectively. One of the major common pathways is the phosphoinositide-3 kinase/AKT-signaling network (PI3K/AKT) that is activated by cytokines and poly IC and has been demonstrated to interact with DISC1 partners (Camargo et al., 2007). Another example is interactions with GSK3 $\beta$, a key regulator of the host inflammatory response and the production of pro- and anti-inflammatory cytokines (Hayden et al., 2006). As described above, DISC1 inhibits GSK3 $\beta$ activity through a direct interaction (Mao et al., 2009). We also found altered poly I:Cinduced phosphorylation of GSK3 $\beta$ in mutant DISC1 newborn mice that might at least in part explain altered basal and poly $\mathrm{I}: \mathrm{C}$-induced production of cytokines in fetal brains and resultant affective behaviors in adult offspring (Abazyan et al., 2010). These observations are consistent with an emerging role for GSK3 $\beta$ in inflammation-associated depression and anxiety (Jope, 2011).

Many immune effects of GSK3 $\beta$ are related to its regulation of critical transcription factors, including nuclear factor kappalight-chain-enhancer of activated B cells (NF-кB; Hayden et al., 2006). A family of TLRs acts as primary sensors that detect a wide variety of microbial components and elicit innate immune responses. All TLR signaling pathways culminate in activation of NF- $\kappa \mathrm{B}$, which controls the expression of an array of inflammatory cytokine genes. Stimulation with TLR ligands triggers the rapid phosphorylation of specific serine residues of inhibitor of $\kappa \mathrm{B}(\mathrm{I} \kappa \mathrm{B})$ proteins by the I $\mathrm{B}$ kinase (IKK) complex. Phosphorylated I $\mathrm{B}$ proteins are subsequently polyubiquitinated and degraded, allowing NF- $\kappa$ B to move into the nucleus. This so-called "canonical pathway" is involved in TLR-mediated induction of inflammatory cytokines such as tumor necrosis factor- $\alpha$ (TNF- $\alpha$ ) and interleukin-6 (IL-6; Hayden et al., 2006). Prior studies with DISC1 have demonstrated that DISC1, particularly a nuclear isoform of the protein, can play an important role in regulation of transcription activity in the nucleus (Sawamura et al., 2008). Our pilot in vitro experiments demonstrated that DISC1 may impact NF- $\kappa \mathrm{B}$ signaling. We found that expression of mutant DISC1 in $\mathrm{N} 2$ a neuronal cells led to delaying a recovery of IкB $\alpha$ after TNF- $\alpha$-induced phosphorylation and ubiquitination of I $\mathrm{B} \alpha$. This prolonged degradation due to expression of mutant DISC1 seems to suggest that perturbation in functions of DISC1 could also affect (e.g., stimulate) pro-inflammatory signaling transduction cascades in neurons.

In addition to immune signaling pathways, DISC1 and perhaps other candidate genes can play a significant role in the cellular processes utilized by microbes during their life cycles (Carter, 2009). It has been proposed that the involvement of DISC1 in the control of the microtubule network might be important both in viral traffic and in the rerouting of microtubules to the vacuoles formed by T. gondii (Carter, 2009).

Recent clinical trials of anti-inflammatory add-on therapy in schizophrenia have demonstrated superior beneficial treatment effects when antipsychotics were co-administered with anti-inflammatory compounds, as compared with treatment outcomes using antipsychotics alone (Meyer et al., 2011). However, a broad non-specific anti-inflammatory or immunosuppressive treatments that may have several unwanted effects such as increased sensitivity to infections (Meyer et al., 2011). Ultimately, future therapeutic approaches will result from deciphering intracellular pathways that underlie convergence of environmental influences and genetic predisposition and their influence on neurodevelopmental processes. 


\section{CONCLUSION REMARKS}

Disrupted in schizophrenia 1-mediated pathways play multiple roles for critical cellular processes through many protein binding partners in a context dependent manner. Nonetheless, it is still unknown which functional aspect of DISC1 directly affects molecular mechanisms underlying disease susceptibility. Are all DISC1 functions in such cellular events implicated in disease processes or are only some specific functional aspects critical? This is a tremendously difficult question, because the molecular disposition of DISC1 is complex as reflected by multiple isoforms at both mRNA and protein levels (Ishizuka et al., 2006; Nakata et al., 2009). Nonetheless, biological functions of DISC1 are currently being explored without waiting for the complete identification of DISC1 isoforms, resulting in the identification of multiple roles of DISC1 in various functional contexts. In fact, in addition to the roles in cerebral cortex we reviewed here, DISC1 also contributes to brain development and function in other brain regions, such as hippocampal regions (Enomoto et al., 2009; Kim et al., 2009; Meyer and Morris, 2009). Further investigations with advanced genetic engineering techniques, which allow us to dissect region and cell type-specific DISC1 functions in a temporal manner, might contribute to

\section{REFERENCES}

Abazyan, B., Nomura, J., Kannan, G., Ishizuka, K., Tamashiro, K. L., Nucifora, F., Pogorelov, V., Ladenheim, B., Yang, C., Krasnova, I. N., Cadet, J. L., Pardo, C., Mori, S., Kamiya, A., Vogel, M. W., Sawa, A., Ross, C. A., and Pletnikov, M. V. (2010). Prenatal interaction of mutant DISC1 and immune activation produces adult psychopathology. Biol. Psychiatry 68, 1172-1181.

Bachmann, R. F., Schloesser, R. J., Gould, T. D., and Manji, H. K. (2005). Mood stabilizers target cellular plasticity and resilience cascades: implications for the development of novel therapeutics. Mol. Neurobiol. 32, 173-202.

Boules, M., Shaw, A., Fredrickson, P., and Richelson, E. (2007). Neurotensin agonists: potential in the treatment of schizophrenia. CNS Drugs 21, 13-23.

Bradshaw, N. J., Christie, S., Soares, D. C., Carlyle, B. C., Porteous, D. J., and Millar, J. K. (2009). NDE1 and NDEL1: multimerisation, alternate splicing and DISC1 interaction. Neurosci. Lett. 449, 228-233.

Brandon, N. J., and Sawa, A. (2011). Linking neurodevelopmental and synaptic theories of mental illness through DISC1. Nat. Rev. Neurosci. 12, 707-722.

Brown, A. S., and Derkits, E. J. (2010). Prenatal infection and schizophrenia: a review of epidemiologic and translational studies. Am. J. Psychiatry 167, 261-280.

Burdick, K. E., Kamiya, A., Hodgkinson, C. A., Lencz, T., DeRosse, P., Ishizuka,
K., Elashvili, S., Arai, H., Goldman, D., Sawa, A., and Malhotra, A. K. (2008). Elucidating the relationship between DISC1, NDEL1 and NDE1 and the risk for schizophrenia: evidence of epistasis and competitive binding. Hum. Mol. Genet. 17, 2462-2473.

Callicott, J. H., Straub, R. E., Pezawas, L., Egan, M. F., Mattay, V. S., Hariri, A. R., Verchinski, B. A., Meyer-Lindenberg, A., Balkissoon, R., Kolachana, B., Goldberg, T. E., and Weinberger, D. R. (2005). Variation in DISC1 affects hippocampal structure and function and increases risk for schizophrenia. Proc. Natl. Acad. Sci. U.S.A. 102, 8627-8632.

Camargo, A. C., Caldo, H., and Emson, P. C. (1983). Degradation of neurotensin by rabbit brain endo-oligopeptidase A and endo-oligopeptidase B (proline-endopeptidase). Biochem. Biophys. Res. Commun. 116, 1151-1159.

Camargo, L. M., Collura, V., Rain, J. C., Mizuguchi, K., Hermjakob, H., Kerrien, S., Bonnert, T. P., Whiting, P. J., and Brandon, N. J. (2007). Disrupted in schizophrenia 1 Interactome: evidence for the close connectivity of risk genes and a potenMol. Psychiatry 12, 74-86.

Carter, C. J. (2009). Schizophrenia susceptibility genes directly pathogens: cytomegalovirus, influenza, herpes simplex, rubella, tial synaptic basis for schizophrenia. implicated in the life cycles of

more clearly elucidate DISC1 functions relevant to psychiatric disorders.

As complete functional recovery is unlikely for neurodevelopmental disorders, such as schizophrenia, developing preventive strategies is particularly important. Indeed, if the findings on microbial etiologies and resultant immune dysfunction are replicated, simple public health measures may prove beneficial in diminishing the incidence of infections during pregnancy to prevent an appreciable proportion of schizophrenia cases. For example, influenza vaccination, improved hygiene to prevent $T$. gondii infection, and antibiotics to treat genital/reproductive infections are feasible strategies already employed (Brown and Derkits, 2010).

\section{ACKNOWLEDGMENTS}

We thank Dr. Hanna Jaaro-Peled and Ms. Sandra P. Zoubovsky for critical reading of the manuscript. We also thank Ms. Yukiko Lema for preparation of the figure. This work was supported by grants from MH091230 (Atsushi Kamiya), MH083728 (Mikhail V. Pletnikov), MH094268 (Atsushi Kamiya; Mikhail V. Pletnikov), and foundation grants from NARSAD (Atsushi Kamiya; Mikhail V. Pletnikov), S-R (Atsushi Kamiya), BSF (Atsushi Kamiya), and SMRI (Mikhail V. Pletnikov).

and Toxoplasma gondii. Schizophr. Bull. 35, 1163-1182.

Chubb, J. E., Bradshaw, N. J., Soares, D. C., Porteous, D. J., and Millar, J. K. (2008). The DISC locus in psychiatric illness. Mol. Psychiatry 13, 36-64.

Dantzer, R., O'Connor, J. C., Freund, G. G., Johnson, R. W., and Kelley, K. W. (2008). From inflammation to sickness and depression: when the immune system subjugates the brain. Nat. Rev. Neurosci. 9 , $46-56$.

DeLisi, L. E., and Wyatt, R. J. (1982). Abnormal immune regulation in schizophrenic patients. Psychopharmacol. Bull. 18, 158-163.

Di Giorgio, A., Blasi, G., Sambataro, F., Rampino, A., Papazacharias, A., Gambi, F., Romano, R., Caforio, G., Rizzo, M., Latorre, V., Popolizio, T., Kolachana, B., Callicott, J. H., Nardini, M., Weinberger, D. R., and Bertolino, A. (2008). Association of the SerCys DISC1 polymorphism with human hippocampal formation gray matter and function during memory encoding. Eur. J. Neurosci. 28, 2129-2136.

Ehninger, D., Sano, Y., de Vries, P. J., Dies, K., Franz, D., Geschwind, D. H., Kaur, M., Lee, Y. S., Li, W., Lowe, J. K., Nakagawa, J. A., Sahin, M., Smith, K., Whittemore, V., and Silva, A. J. (2012). Gestational immune activation and Tsc2 haploinsufficiency cooperate to disrupt fetal survival and may perturb social behavior in adult mice. Mol. Psychiatry 17, 62-70.
Enomoto, A., Asai, N., Namba, T., Wang, Y., Kato, T., Tanaka, M. Tatsumi, H., Taya, S., Tsuboi, D., Kuroda, K., Kaneko, N., Sawamoto, K., Miyamoto, R., Jijiwa, M., Murakumo, Y., Sokabe, M., Seki, T., Kaibuchi, K., and Takahashi, M. (2009). Roles of disrupted-inschizophrenia 1-interacting protein girdin in postnatal development of the dentate gyrus. Neuron 63, 774-787.

Fu, C. A., Shen, M., Huang, B. C., Lasaga, J., Payan, D. G., and Luo, Y. (1999). TNIK, a novel member of the germinal center kinase family that activates the c-Jun N-terminal kinase pathway and regulates the cytoskeleton. J. Biol. Chem. 274, 30729-30737.

Glatt, S. J., Everall, I. P., Kremen, W. S., Corbeil, J., Sasik, R., Khanlou, N., Han, M., Liew, C. C., and Tsuang, M. T. (2005). Comparative gene expression analysis of blood and brain provides concurrent validation of SELENBP1 up-regulation in schizophrenia. Proc. Natl. Acad. Sci. U.S.A. 102, 15533-15538.

Hattori, T., Baba, K., Matsuzaki, S., Honda, A., Miyoshi, K., Inoue, K., Taniguchi, M., Hashimoto, H., Shintani, N., Baba, A., Shimizu, S., Yukioka, F., Kumamoto, N., Yamaguchi, A., Tohyama, M., and Katayama, T. (2007). A novel DISC1-interacting partner DISC1binding zinc-finger protein: implication in the modulation of DISC1dependent neurite outgrowth. Mol. Psychiatry 12, 398-407. 
Hayashi, M. A., Portaro, F. C., Bastos, M. F., Guerreiro, J. R., Oliveira, V., Gorrao, S. S., Tambourgi, D. V., Sant'Anna, O. A., Whiting, P. J., Camargo, L. M., Konno, K., Brandon, N. J., and Camargo, A. C. (2005). Inhibition of NUDEL (nuclear distribution element-like)oligopeptidase activity by disruptedin-schizophrenia 1. Proc. Natl. Acad. Sci. U.S.A. 102, 3828-3833.

Hayashi-Takagi, A., Takaki, M., Graziane, N., Seshadri, S., Murdoch, H., Dunlop, A. J., Makino, Y., Seshadri, A. J., Ishizuka, K., Srivastava, D. P., Xie, Z., Baraban, J. M., Houslay, M. D., Tomoda, T., Brandon, N. J., Kamiya, A., Yan, Z., Penzes, P., and Sawa, A. (2010). Disrupted-in-schizophrenia 1 (DISC1) regulates spines of the glutamate synapse via Racl. Nat. Neurosci. 13, 327-332.

Hayden, M. S., West, A. P., and Ghosh, S. (2006). NF-kappaB and the immune response. Oncogene 25, 6758-6780.

Hennah, W., Varilo, T., Kestila, M., Paunio, T., Arajarvi, R., Haukka, J., Parker, A., Martin, R., Levitzky, S., Partonen, T., Meyer, J., Lonnqvist, J., Peltonen, L., and Ekelund, J. (2003). Haplotype transmission analysis provides evidence of association for DISC1 to schizophrenia and suggests sex-dependent effects. Hum. Mol. Genet. 12, 3151-3159.

Hirotsune, S., Fleck, M. W., Gambello, M. J., Bix, G. J., Chen, A., Clark, G. D., Ledbetter, D. H., McBain, C. J., and Wynshaw-Boris, A. (1998). Graded reduction of Pafah1b1 (Lis1) activity results in neuronal migration defects and early embryonic lethality. Nat. Genet. 19, 333-339.

Hodgkinson, C. A., Goldman, D., Jaeger, J., Persaud, S., Kane, J. M., Lipsky, R. H., and Malhotra, A. K. (2004). Disrupted in schizophrenia 1 (DISC1): association with schizophrenia, schizoaffective disorder, and bipolar disorder. Am. J. Hum. Genet. 75, 862-872.

Hur, E. M., and Zhou, F. Q. (2010). GSK3 signalling in neural development. Nat. Rev. Neurosci. 11, 539-551.

Ibi, D., Nagai, T., Koike, H., Kitahara, Y., Mizoguchi, H., Niwa, M., Jaaro-Peled, H., Nitta, A., Yoneda, Y., Nabeshima, T., Sawa, A., and Yamada, K. (2010). Combined effect of neonatal immune activation and mutant DISCl on phenotypic changes in adulthood. Behav. Brain Res. 206, 32-37.

Ishizuka, K., Kamiya, A., Oh, E. C., Kanki, H., Seshadri, S., Robinson, J. F., Murdoch, H., Dunlop, A. J., Kubo,
K., Furukori, K., Huang, B., Zeledon, M., Hayashi-Takagi, A., Okano, H., Nakajima, K., Houslay, M. D., Katsanis, N., and Sawa, A. (2011). DISC1dependent switch from progenitor proliferation to migration in the developing cortex. Nature 473, 92-96.

Ishizuka, K., Paek, M., Kamiya, A., Sawa, A. (2006). A review of disrupted-inschizophrenia-1 (DISC1): neurodevelopment, cognition, and mental conditions. Biol. Psychiatry 59, 1189-1197.

Izzo, J. L. Jr., and Weir, M. R. (2011). Angiotensin-converting enzyme inhibitors. J. Clin. Hypertens. (Greenwich) 13, 667-675.

Jope, R. S. (2011). Glycogen synthase kinase-3 in the etiology and treatment of mood disorders. Front. Mol. Neurosci. 4:16. doi:10.3389/fnmol.2011.00016

Kamiya, A., Kubo, K., Tomoda, T., Takaki, M., Youn, R., Ozeki, Y., Sawamura, N., Park, U., Kudo, C., Okawa, M., Ross, C. A., Hatten, M. E., Nakajima, K., and Sawa, A. (2005). A schizophrenia-associated mutation of DISC1 perturbs cerebral cortex development. Nat. Cell Biol. 7, 1167-1178.

Kamiya, A., Tan, P. L., Kubo, K., Engelhard, C., Ishizuka, K., Kubo, A., Tsukita, S., Pulver, A. E., Nakajima, K., Cascella, N. G., Katsanis, N., and Sawa, A. (2008). Recruitment of PCM1 to the centrosome by the cooperative action of DISC1 and BBS4: a candidate for psychiatric illnesses. Arch. Gen. Psychiatry 65, 996-1006.

Kang, U. G., Seo, M. S., Roh, M. S., Kim, Y., Yoon, S. C., and Kim, Y. S. (2004). The effects of clozapine on the GSK3-mediated signaling pathway. FEBS Lett. 560, 115-119.

Kilpinen, H., Ylisaukko-Oja, T., Hennah, W., Palo, O. M., Varilo, T., Vanhala, R., Nieminen-von Wendt, T., von Wendt, L., Paunio, T., and Peltonen, L. (2008). Association of DISC1 with autism and Asperger syndrome. Mol. Psychiatry 13, 187-196.

Kim, J. Y., Duan, X., Liu, C. Y., Jang, M. H., Guo, J. U., Pow-anpongkul, N., Kang, E., Song, H., and Ming, G. L. (2009). DISC1 regulates new neuron development in the adult brain via modulation of AKT-mTOR signaling through KIAA1212. Neuron 63, 761-773.

Kubo, K., Tomita, K., Uto, A., Kuroda, K., Seshadri, S., Cohen, J., Kaibuchi, K., Kamiya, A., and Nakajima, K. (2010). Migration defects by DISC1 knockdown in C57BL/6, 129X1/SvJ, and ICR strains via in utero gene transfer and virus-mediated RNAi. Biochem. Biophys. Res. Commun. 400, 631-637.

Li, X., Rosborough, K. M., Friedman, A. B., Zhu, W., and Roth, K. A. (2007). Regulation of mouse brain glycogen synthase kinase- 3 by atypical antipsychotics. Int. J. Neuropsychopharmacol. 10, 7-19.

Mahmoudi, T., Li, V. S., Ng, S. S., Taouatas, N., Vries, R. G., Mohammed, S., Heck, A. J., and Clevers, H. (2009). The kinase TNIK is an essential activator of Wnt target genes. EMBO J. 28, 3329-3340.

Mao, Y., Ge, X., Frank, C. L., Madison, J. M., Koehler, A. N., Doud, M. K., Tassa, C., Berry, E. M., Soda, T., Singh, K. K., Biechele, T., Petryshen, T. L., Moon, R. T., Haggarty, S. J., and Tsai, L. H. (2009). Disrupted in schizophrenia 1 regulates neuronal progenitor proliferation via modulation of GSK3beta/beta-catenin signaling. Cell 136, 1017-1031.

Mathieson, I., Munafo, M. R., and Flint, J. (2011). Meta-analysis indicates that common variants at the DISC1 locus are not associated with schizophrenia. Mol. Psychiatry. doi: 10.1038/mp.2011.41. [Epub ahead of print].

Matigian, N., Windus, L., Smith, H., Filippich, C., Pantelis, C., McGrath, J., Mowry, B., and Hayward, N. (2007). Expression profiling in monozygotic twins discordant for bipolar disorder reveals dysregulation of the WNT signalling pathway. Mol. Psychiatry 12, 815-825.

Meyer, K. D., and Morris, J. A. (2009). Discl regulates granule cell migration in the developing hippocampus. Hum. Mol. Genet. 18, 3286-3297.

Meyer, U., Schwarz, M. J., and Muller, N. (2011). Inflammatory processes in schizophrenia: a promising neuroimmunological target for the treatment of negative/cognitive symptoms and beyond. Pharmacol. Ther. 132, 96-110.

Millar, J. K., Pickard, B. S., Mackie, S. James, R., Christie, S., Buchanan, S. R., Malloy, M. P., Chubb, J. E., Huston, E., Baillie, G. S., Thomson, P. A., Hill, E. V., Brandon, N. J., Rain, J. C., Camargo, L. M., Whiting, P. J., Houslay, M. D., Blackwood, D. H., Muir, W. J., and Porteous, D. J. (2005). DISC1 and PDE4B are interacting genetic factors in schizophrenia that regulate cAMP signaling. Science 310, 1187-1191.

Millar, J. K., Wilson-Annan, J. C., Anderson, S., Christie, S., Taylor, M. S., Semple, C. A., Devon, R. S., St Clair, D. M., Muir, W. J., Blackwood, D. H., and Porteous, D. J. (2000).
Disruption of two novel genes by a translocation co-segregating with schizophrenia. Hum. Mol. Genet. 9, 1415-1423.

Miller, A. H., Maletic, V., and Raison, C. L. (2009). Inflammation and its discontents: the role of cytokines in the pathophysiology of major depression. Biol. Psychiatry 65, 732-741.

Miyoshi, K., Asanuma, M., Miyazaki, I., Diaz-Corrales, F. J., Katayama, T., Tohyama, M., and Ogawa, N. (2004). DISC1 localizes to the centrosome by binding to kendrin. Biochem. Biophys. Res. Commun. 317, 1195-1199.

Miyoshi, K., Honda, A., Baba, K. Taniguchi, M., Oono, K., Fujita, T., Kuroda, S., Katayama, T., Tohyama, M. (2003). Disrupted-inschizophrenia 1, a candidate gene for schizophrenia, participates in neurite outgrowth. Mol. Psychiatry 8, 685-694.

Morris, J. A., Kandpal, G., Ma, L., Austin, C. P. (2003). DISC1 (disrupted-inschizophrenia 1) is a centrosomeassociated protein that interacts with MAP1A, MIPT3, ATF4/5 and NUDEL: regulation and loss of interaction with mutation. Hum. Mol. Genet. 12, 1591-1608.

Nakata, K., Lipska, B. K., Hyde, T. M., Ye, T., Newburn, E. N., Morita, Y., Vakkalanka, R., Barenboim, M., Sei, Y., Weinberger, D. R., and Kleinman, J. E. (2009). DISC1 splice variants are upregulated in schizophrenia and associated with risk polymorphisms. Proc. Natl. Acad. Sci. U.S.A. 106, 15873-15878.

Nakata, K., Ujike, H., Sakai, A., Takaki, M., Imamura, T., Tanaka, Y., and Kuroda, S. (2003). The human dihydropyrimidinase-related protein 2 gene on chromosome $8 \mathrm{p} 21$ is associated with paranoid-type schizophrenia. Biol. Psychiatry 53 571-576.

Osbun, N., Li, J., O’Driscoll, M. C., Strominger, Z., Wakahiro, M., Rider, E., Bukshpun, P., Boland, E., Spurrell, C. H., Schackwitz, W., Pennacchio, L. A., Dobyns, W. B., Black, G. C., and Sherr, E. H. (2011). Genetic and functional analyses identify DISC1 as a novel callosal agenesis candidate gene. Am. J. Med. Genet. A 155A, 1865-1876.

Ozeki, Y., Tomoda, T., Kleiderlein, J., Kamiya, A., Bord, L., Fujii, K., Okawa, M., Yamada, N., Hatten, M. E., Snyder, S. H., Ross, C. A. and Sawa, A. (2003). Disrupted-inschizophrenia-1 (DISC-1): mutant truncation prevents binding to NudE-like (NUDEL) and inhibits neurite outgrowth. Proc. Natl. Acad. Sci. U.S.A. 100, 289-294. 
Park, Y. U., Jeong, J., Lee, H., Mun, J. Y., Kim, J. H., Lee, J. S., Nguyen, M. D., Han, S. S., Suh, P. G., and Park, S. K. (2010). Disrupted-in-schizophrenia 1 (DISC1) plays essential roles in mitochondria in collaboration with Mitofilin. Proc. Natl. Acad. Sci. U.S.A. 107, 17785-17790.

Patterson, P. H. (2007). Neuroscience. maternal effects on schizophrenia risk. Science 318, 576-577.

Pilz, D. T., Matsumoto, N., Minnerath, S., Mills, P., Gleeson, J. G., Allen, K. M., Walsh, C. A., Barkovich, A. J., Dobyns, W. B., Ledbetter, D. H., and Ross, M. E. (1998). LIS1 and XLIS (DCX) mutations cause most classical lissencephaly, but different patterns of malformation. Hum. Mol. Genet. 7, 2029-2037.

Porteous, D. J., Millar, J. K., Brandon, N. J., and Sawa, A. (2011). DISC1 at 10: connecting psychiatric genetics and neuroscience. Trends. Mol. Med. 17, 699-706.

Potkin, S. G., Turner, J. A., Guffanti, G., Lakatos, A., Fallon, J. H., Nguyen, D. D., Mathalon, D., Ford, J., Lauriello, J., and Macciardi, F. (2009). A genome-wide association study of schizophrenia using brain activation as a quantitative phenotype. Schizophr. Bull. 35, 96-108.

Prata, D. P., Mechelli, A., Fu, C. H., Picchioni, M., Kane, F., Kalidindi, S., McDonald, C., Kravariti, E., Toulopoulou, T., Miorelli, A., Murray, R., Collier, D. A., and McGuire, P. K. (2008). Effect of disrupted-inschizophrenia-1 on pre-frontal cortical function. Mol. Psychiatry 13, 909, 915-917.

Purcell, S. M., Wray, N. R., Stone, J. L., Visscher, P. M., O’Donovan, M. C., Sullivan, P. F., and Sklar, P. (2009). Common polygenic variation contributes to risk of schizophrenia and bipolar disorder. Nature 460, 748-752.

Rowe, M. K., Wiest, C., and Chuang, D. M. (2007). GSK-3 is a viable potential target for therapeutic intervention in bipolar disorder. Neurosci. Biobehav. Rev. 31, 920-931.

Sawamura, N., Ando, T., Maruyama, Y., Fujimuro, M., Mochizuki, H., Honjo, K., Shimoda, M., Toda, H., Sawamura-Yamamoto, T., Makuch, L. A., Hayashi, A., Ishizuka, K., Cascella, N. G., Kamiya, A., Ishida, N., Tomoda, T., Hai, T., FurukuboTokunaga, K., and Sawa, A. (2008). Nuclear DISC1 regulates CREmediated gene transcription and sleep homeostasis in the fruit fly. Mol. Psychiatry 13, 1069, 1138-1148.

Sham, P. C., O’Callaghan, E., Takei, N., Murray, G. K., Hare, E. H., and
Murray, R. M. (1992). Schizophrenia following pre-natal exposure to influenza epidemics between 1939 and 1960. Br. J. Psychiatry 160, 461-466.

Shi, J., Levinson, D. F., Duan, J., Sanders, A. R., Zheng, Y., Pe'er, I., Dudbridge, F., Holmans, P. A., Whittemore, A. S., Mowry, B. J., Olincy, A., Amin, F., Cloninger, C. R., Silverman, J. M., Buccola, N. G., Byerley, W. F., Black, D. W., Crowe, R. R., Oksenberg, J. R., Mirel, D. B., Kendler, K. S., Freedman, R., and Gejman, P. V. (2009). Common variants on chromosome 6 p22.1 are associated with schizophrenia. Nature 460, 753-757.

Shinoda, T., Taya, S., Tsuboi, D., Hikita, T., Matsuzawa, R., Kuroda, S., Iwamatsu, A., and Kaibuchi, K. (2007). DISC1 regulates neurotrophin-induced axon elongation via interaction with Grb2. J. Neurosci. 27, 4-14.

Singh, K. K., Ge, X., Mao, Y., Drane, L., Meletis, K., Samuels, B. A., and Tsai, L. H. (2010). Dixdc1 is a critical regulator of DISC1 and embryonic cortical development. Neuron 67, 33-48.

Soares, D. C., Carlyle, B. C., Bradshaw, N. J., and Porteous, D. J. (2011). DISC1: structure, function, and therapeutic potential for major mental illness. ACS Chem. Neurosci. 2, 609-632.

Song, W., Li, W., Feng, J., Heston, L. L., Scaringe, W. A., and Sommer, S. S. (2008). Identification of high risk DISC1 structural variants with a $2 \%$ attributable risk for schizophrenia. Biochem. Biophys. Res. Commun. 367, 700-706.

Song, W., Li, W., Noltner, K., Yan, J., Green, E., Grozeva, D., Jones, I. R., Craddock, N., Longmate, J., Feng, J., and Sommer, S. S. (2010). Identification of high risk DISC1 protein structural variants in patients with bipolar spectrum disorder. Neurosci. Lett. 486, 136-140.

Stambolic, V., Ruel, L., and Woodgett, J. R. (1996). Lithium inhibits glycogen synthase kinase- 3 activity and mimics wingless signalling in intact cells. Curr. Biol. 6, 1664-1668.

Stefansson, H., Ophoff, R. A., Steinberg, S., Andreassen, O. A., Cichon, S., Rujescu, D., Werge, T., Pietilainen, O. P., Mors, O., Mortensen, P. B., Sigurdsson, E., Gustafsson, O., Nyegaard, M., Tuulio-Henriksson, A., Ingason, A., Hansen, T., Suvisaari, J., Lonnqvist, J., Paunio, T., Borglum, A. D., Hartmann, A., Fink-Jensen, A., Nordentoft, M., Hougaard, D., Norgaard-Pedersen, B., Bottcher, Y., Olesen, J., Breuer, R., Moller, H. J., Giegling, I., Rasmussen, H. B.,
Timm, S., Mattheisen, M., Bitter, I., Rethelyi, J. M., Magnusdottir, B. B. Sigmundsson, T., Olason, P., Masson, G., Gulcher, J. R., Haraldsson, M., Fossdal, R., Thorgeirsson, T. E., Thorsteinsdottir, U., Ruggeri, M., Tosato, S., Franke, B., Strengman, E., Kiemeney, L. A., Melle, I., Djurovic, S., Abramova, L., Kaleda, V., Sanjuan, J., de Frutos, R., Bramon, E., Vassos, E., Fraser, G., Ettinger, U., Picchioni, M., Walker, N., Toulopoulou, T., Need, A. C., Ge, D., Yoon, J. L., Shianna, K. V., Freimer, N. B., Cantor, R. M., Murray, R., Kong, A., Golimbet, V., Carracedo, A., Arango, C., Costas, J., Jonsson, E. G., Terenius, L., Agartz, I., Petursson, H., Nothen, M. M., Rietschel, M., Matthews, P. M., Muglia, P., Peltonen, L., St Clair, D., Goldstein, D. B., Stefansson, K., and Collier, D. A. (2009). Common variants conferring risk of schizophrenia. Nature 460, 744-747.

Taira, K., Umikawa, M., Takei, K., Myagmar, B. E., Shinzato, M., Machida, N., Uezato, H., Nonaka, S., and Kariya, K. (2004). The Traf2- and Nck-interacting kinase as a putative effector of Rap2 to regulate actin cytoskeleton. J. Biol. Chem. 279, 49488-49496.

Taya, S., Shinoda, T., Tsuboi, D., Asaki, J., Nagai, K., Hikita, T., Kuroda, S., Kuroda, K., Shimizu, M., Hirotsune, S., Iwamatsu, A., and Kaibuchi, K. (2007). DISC1 regulates the transport of the NUDEL/LIS1/14-33epsilon complex through kinesin1. J. Neurosci. 27, 15-26.

Thomson, P. A., Harris, S. E., Starr, J. M., Whalley, L. J., Porteous, D. J., and Deary, I. J. (2005). Association between genotype at an exonic SNP in DISC1 and normal cognitive aging. Neurosci. Lett. 389 , 41-45.

Tomppo, L., Hennah, W., Lahermo, P., Loukola, A., Tuulio-Henriksson, A. Suvisaari, J., Partonen, T., Ekelund, J., Lonnqvist, J., and Peltonen, L. (2009a). Association between genes of disrupted in schizophrenia 1 (DISC1) interactors and schizophrenia supports the role of the DISC1 pathway in the etiology of major mental illnesses. Biol. Psychiatry 65 1055-1062.

Tomppo, L., Hennah, W., Miettunen, J., Jarvelin, M. R., Veijola, J., Ripatti, S., Lahermo, P., Lichtermann, D., Peltonen, L., and Ekelund, J. (2009b). Association of variants in DISC1 with psychosis-related traits in a large population cohort. Arch. Gen. Psychiatry 66, 134-141.

Torrey, E. F., and Yolken, R. H. (2003) Toxoplasma gondii and schizo- phrenia. Emerging Infect. Dis. 9 1375-1380.

Wang, Q., Charych, E. I., Pulito, V. L., Lee, J. B., Graziane, N. M., Crozier, R. A., Revilla-Sanchez, R., Kelly, M. P., Dunlop, A. J., Murdoch, H., Taylor, N., Xie, Y., Pausch, M., HayashiTakagi, A., Ishizuka, K., Seshadri, S., Bates, B., Kariya, K., Sawa, A., Weinberg, R. J., Moss, S. J., Houslay, M. D., Yan, Z., and Brandon, N. J. (2011). The psychiatric disease risk factors DISC1 and TNIK interact to regulate synapse composition and function. Mol. Psychiatry 16, 1006-1023.

Yamada, M., Yoshida, Y., Mori, D., Takitoh, T., Kengaku, M., Umeshima, H., Takao, K., Miyakawa, T., Sato, M., Sorimachi, H., Wynshaw-Boris, A., and Hirotsune, S. (2009). Inhibition of calpain increases LIS1 expression and partially rescues in vivo phenotypes in a mouse model of lissencephaly. Nat. Med. 15, 1202-1207.

Yoshimura, T., Kawano, Y., Arimura, N., Kawabata, S., Kikuchi, A., and Kaibuchi, K. (2005). GSK-3beta regulates phosphorylation of CRMP2 and neuronal polarity. Cell 120, 137-149.

Young-Pearse, T. L., Suth, S., Luth, E. S., Sawa, A., and Selkoe, D. J. (2010). Biochemical and functional interaction of disrupted-inschizophrenia 1 and amyloid precursor protein regulates neurona migration during mammalian cortical development. J. Neurosci. 30, 10431-10440.

Conflict of Interest Statement: The authors declare that the research was conducted in the absence of any commercial or financial relationships that could be construed as a potential conflict of interest.

Received: 24 December 2011; accepted: 06 March 2012; published online: 22 March 2012.

Citation: Kamiya A, Sedlak TW and Pletnikov MV (2012) DISC1 pathway in brain development: exploring therapeutic targets for major psychiatric disorders. Front. Psychiatry 3:25. doi: 10.3389/fpsyt.2012.00025

This article was submitted to Frontiers in Molecular Psychiatry, a specialty of Frontiers in Psychiatry.

Copyright (c) 2012 Kamiya, Sedlak and Pletnikov. This is an open-access article distributed under the terms of the Creative Commons Attribution Non Commercial License, which permits noncommercial use, distribution, and reproduction in other forums, provided the original authors and source are credited. 